\begin{tabular}{|c|c|c|c|c|c|}
\hline Month & $\begin{array}{l}\text { Total } \\
\text { Cases } \\
\text { (n) }\end{array}$ & $\begin{array}{l}\text { Radial } \\
\text { Cases } \\
\text { (n) }\end{array}$ & $\begin{array}{l}\text { Percent of Cases } \\
\text { with Radial Access } \\
\text { (\% total) }\end{array}$ & $\begin{array}{l}\text { Diagnostic } \\
\text { Radial } \\
\text { Cases(n) }\end{array}$ & $\begin{array}{l}\text { Interventional } \\
\text { Radial cases } \\
\text { (n) }\end{array}$ \\
\hline October 2019 & 87 & 9 & $10.3 \%$ & 9 & 0 \\
\hline November & 78 & 10 & $12.8 \%$ & 6 & 4 \\
\hline \multicolumn{6}{|l|}{2019} \\
\hline December 2019 & 70 & 20 & $28.6 \%$ & 14 & 6 \\
\hline January 2019 & 80 & 23 & $28.8 \%$ & 17 & 6 \\
\hline February 2019 & 72 & 28 & $38.9 \%$ & 24 & 4 \\
\hline
\end{tabular}

performed with radial access, for a total crossover rate of $4.3 \%$. The use of radial access as a proportion of total case volume increased from $10.3 \%$ in October 2019 to $38.9 \%$ in February 2020 (table 1). A total of 20 radial interventional procedures were performed during the time period studied including flow diversion, middle meningeal artery embolization, epistaxis embolization, coiling, and thrombectomy.

Conclusion Our single-center series demonstrates low crossover rates from transradial to transfemoral of $4.3 \%$, and shows that widespread adoption of this method can be successfully achieved in a period of a few months. Although radial access presents its own challenges, it is feasible to perform many diverse neuroendovascular cases by this route.

Disclosures K. Dakay: None. G. Kaur: None. J. Santarelli: None. C. Gandhi: None. F. Al-Mufti: None.

\section{E-167 IMAGING OPTIMIZATION FOR FLOW DIVERSION IN C- ARM CONE BEAM COMPUTED TOMOGRAPHY}

1,2D Dornbos III*, 2,3J DiNitto, 1,2L Elijovich, 1,2D Hoit, 1,2 $\mathrm{V}$ Inoa-Acosta, ${ }^{1,2} \mathrm{C}$ Nickele, ${ }^{4}$ E Duckworth, ${ }^{1,2}$ A Arthur. ${ }^{1}$ Neurological Surgery, Semmes-Murphey Clinic, Memphis, TN; ${ }^{2}$ Neurological Surgery, University of Tennessee Health Science Center, Memphis, TN; ${ }^{3}$ Siemens Medical Solutions, Malvern, PA; ${ }^{4}$ Neurological Surgery, St. Luke's Health System, Boise, ID

10.1136/neurintsurg-2020-SNIS.199

Introduction Contrast usage for Cone Beam Angiographic Computed Tomography (CBCTA) performance has limited efficacy for simultaneous visualization of vasculature, implanted devices, and surrounding tissue. Optimal windowing of CBCTA images in order to simultaneously visualize both low attenuating brain parenchyma and high attenuating flow diverters remains a significant challenge. Appropriate dilution of contrast has the potential to reduce the gray scale value on the vasculature and allow enhanced simultaneous visibility of tissue and parent artery. Currently, there has been limited work done pertaining to optimal contrast dilution in CBCTA. $^{1}{ }^{2}$ We present an in vivo study aimed to identify optimal contrast dilution to improve image quality in the setting of flow diverting stents.

Methods Cone beam CT-based computed angiographic imaging (20 s DR, Syngo DynaCT, Siemens Healthineers, Forchheim, Germany) was performed on 10 patients following placement of a Pipeline (Medtronic USA) flow diverting stent. Cone beam CT imaging was acquired with selective internal carotid artery catheterization utilizing 5 different contrast percentages $(5,10,15,20$, and $25 \%)$ with a constant flow rate of $3 \mathrm{~mL} /$ $\mathrm{sec}$ and $80 \mathrm{cc}$ of contrast. Gray scale values were averaged for pertinent structures (parent artery, Pipeline device, bone, and background) using region of interest (ROI) analysis of respective Hounsfield units. Contrast to noise ratio (CNR) was used for measurement. Contrast dilution that allows matched CNR in both bone and the parent artery provides ideal visualization.

Results In the 10 patients evaluated in this study, evaluation of bone and parent vessel CNR identified 15\% contrast as optimal for visualization of the Pipeline embolization device within the parent artery (figure 1A). Other contrast concentrations had greater observed differences between bone and parent vessel CNR (figure 1B) and decreased visualization of the flow-diverting device.

Conclusion The concentration of contrast administered during Cone Beam Angiographic Computed Tomography has a substantial impact on the attenuation of surrounding structures (bone, parenchyma), which can impair simultaneous visualization of the parent vessel and implanted device. Based on this analysis, $15 \%$ contrast dilution optimizes visualization of the Pipeline embolization device and its position within the parent artery.

\section{REFERENCES}

1. Duckworth, et al., Optimizing contrast-enhanced cone-beam CT protocol to facilitate simultaneous visualization of neurovascular pathologies and surrounding structures of interest. Interventional Neuroradiology 2019;7(1):102-110. 
2. DiNitto, et al., Optimization of device visualization for C-arm conebeam computed tomography in the angiography suite. Journal of Neurointerventional Surgery 2018; 10:A80

Disclosures D. Dornbos: None. J. DiNitto: 5; C; Siemens Medical Solutions. L. Elijovich: 1; C; Siemens Medical Solutions. D. Hoit: 1; C; Siemens Medical Solutions. V. InoaAcosta: 1; C; Siemens Medical Solutions. C. Nickele: 1; C; Siemens Medical Solutions. E. Duckworth: None. A. Arthur: 1; C; Siemens Medical Solutions.

\section{E-168 ADDED VALUE OF MR VESSEL WALL IMAGING IN SPONTANEOUS INTRACRANIAL DISSECTING ANEURYSMS}

${ }^{1} \mathrm{R}$ Abdalla, ${ }^{1} \mathrm{Y}$ Moazeni* ${ }^{2} \mathrm{~A}$ Shaibani, ${ }^{2} \mathrm{M}$ Hurley, ${ }^{2} \mathrm{M}$ Potts, ${ }^{2} \mathrm{~B}$ Jahromi, ${ }^{3} \mathrm{~S}$ Ansari. ${ }^{1}$ Radiology, Northwestern University - Feinberg school of Medicine, Chicago, IL; ${ }^{2}$ Radiology, Neurosurgery, Northwestern University - Feinberg school of Medicine, Chicago, IL; ${ }^{3}$ Radiology, Neurosurgery and Neurology, Northwestern University - Feinberg school of Medicine, Chicago, IL

\subsection{6/neurintsurg-2020-SNIS.200}

Purpose Dissecting intracranial aneurysms (DIA) can present with subarachnoid hemorrhage or ischemia, and are more common in the posterior circulation. Radiographically, DIA have similar morphological features to fusiform and dolichoectatic atherosclerotic aneurysms, with difficult diagnosis on traditional CTA and MRI/MRA cross sectional imaging. In addition, the rebleeding risk from ruptured DIA is considerably higher reaching up to $71.4 \%$ with $46.7 \%$ mortality, necessitating early diagnosis and treatment. We aimed to distinguish specific imaging features of spontaneous DIA using high resolution MR vessel wall imaging (VWI).

Methods In a retrospective analysis of our MR VWI database between Jan 2016 and March 2019, we identified patients with suspected DIA diagnosed by clinical history, CTA/MRA imaging findings, and conventional angiography. MRI 3D TOF and MR VWI were reviewed by two neuroradiologists for imaging findings that were diagnostic for DIA including intramural hematomas, intimal flaps and double lumen. Following diagnosis on MRI/3D TOF MRA, MR VWI was serially assessed for additional findings that could aid or confirm the diagnosis.

Results Seven patients (4M:3F) with mean age $62 \pm 13.7$ were proven to have DIA, all located in the posterior circulation (6 vertebral:1 basilar). All patients presented with either severe headaches or diplopia/dizziness. There was no family history of IA, but high incidence of hypertension and hyperlipidemia (30\%). On MRI/3D TOF MRA, intramural hemorrhage was observed to diagnose two DIAs, which was also confirmed with intramural T1 hyperintense signal on MR VWI. Two aneurysms demonstrated fusiform morphology with intraluminal thrombus on MRI/3D TOF MRA without diagnosis, however, MR VWI identified an enhancing dissection flap and double lumen pathology for definitive DIA diagnosis. Two DIA were suspected with suggestion of intimal flap on MRI/3DTOF MRA, but improved visualization of enhancing intimal flap on MR VWI confirmed the diagnosis. One aneurysm was diagnosed based on clinical history and an associated enhancing dissection flap with tapered occlusion of the contralateral vertebral artery, but no imaging features on 3D TOF MRA or MR VWI suggested a dissecting aneurysm.
Conclusions Spontaneous DIA are more commonly diagnosed in the posterior circulation. MR VWI is a valuable tool in confirming the diagnosis and differentiating fusiform thrombosed aneurysms from DIA with improved visualization of T1 hyperintense intramural hemorrhage, and enhancing intimal flap, and/or double lumen intracranial dissection pathology.

Disclosures R. Abdalla: None. Y. Moazeni: None. A. Shaibani: None. M. Hurley: None. M. Potts: None. B. Jahromi: None. S. Ansari: None.

\section{E-169 INSTITUTIONAL EXPERIENCE FROM 750 NEUROENDOVASCULAR PROCEDURES USING TRANSRADIAL APPROACH - A PROSPECTIVE OBSERVATIONAL STUDY}

${ }^{1} \mathrm{E}$ Almallouhi*, ${ }^{2} \mathrm{~S}$ Al kasab, ${ }^{2} \mathrm{~S}$ Pai, ${ }^{2} \mathrm{~J}$ Lena, ${ }^{2} \mathrm{~A}$ Spiotta. ${ }^{1}$ Medical University of South Carolina, Charleston, SC; ${ }^{2}$ Neurosurgery, Medical University of South Carolina, Charleston, SC

\subsection{6/neurintsurg-2020-SNIS.201}

Background More evidence is emerging in the last two years regarding the feasibility of using transradial approach (TRA) for most neuroendovascular procedures. In addition, TRA has better safety profile and patient satisfaction compared to the traditional transfemoral approach. In this study, we present our experience in transitioning the 'radial-first' approach over a course of one year.

Methods We prospectively collected demographic and procedural variables of all patients who underwent neuroendovascular procedure using the TRA between starting from March 2019. Exclusion criteria included: 1) known vasoocclusive disease such as Raynaud disease, Takayasu arteritis, or thromboangiitis obliterans; 2) known complex radial or brachiocephalic anatomy such as aberrant right subclavian artery or situs inversus; 3 ) procedures that require the use of devices that are larger than 8-French. Predefined interim analyses were planned at 500, 750 and 1000 patients.

Results A total of 750 patients included in this analysis (615 underwent cerebral angiogram and 135 underwent an interventional procedure). Mean age was 55.8 ( \pm 15.1$), 442$ (58.9\%) were females, and 434 (57.9\%) underwent the procedure in outpatient setting. The right radial artery was used in $730(97.3 \%)$ cases, ulnar artery in $16(2.1 \%)$, and left radial artery in $4(0.5 \%)$ cases. A $4 / 5$-French slender sheath was used for cerebral angiograms and a 5/6 or 6/7-French slender sheath was used for interventional procedures. Interventional procedures included flow diversion in 27 cases, 25 cerebral aneurysm primary coiling cases, 17 stent-assisted coiling cases, 11 balloon-assisted coiling cases, 26 tumor and middle meningeal artery (MMA) embolization cases, and 7 mechanical thrombectomy cases. The overall success rate was 94.8\% (711/ 750): $95.4 \%(587 / 615)$ for cerebral angiograms and $91.9 \%$ $(124 / 135)$ for patients who received an intervention. Overall success rate improved from $93.3 \%$ in the first 3 months of the study to $98.3 \%$ in the last 3 months $(\mathrm{P}=0.049)$. Complications related to access sites were seen in 7 (0.9\%) patients: 5 patients had forearm hematoma and 2 had prolonged vasospasm/arm pain that resolved with conservative management. Other complications included post-procedural stroke in 2 patients and sent thrombosis in 1 patient.

Conclusion Incorporation of radial-first approach for neuroendovascular procedures is safe and feasible. TRA is associated 